\title{
NOVOS DESAFIOS PARA UMA GEOPOLÍTICA DO CONHECIMENTO. O CASO DO ESPAÇO EUROPEU DE EDUCAÇÃO SUPERIOR (EEES) E A METODOLOGIA DE APRENDIZAGEM-SERVIÇO COMO RECURSO
}

\author{
NEW CHALLENGES FOR A GEOPOLITICS OF KNOWLEDGE. THE \\ EUROPEAN HIGHER EDUCATION AREA AND THE SERVICE- \\ LEARNING METHODOLOGY AS A CASE IN POINT
}

\begin{abstract}
Carmen Villarino Pardo
Doutora em Literatura Brasileira e Professora Titular de Literatura Brasileira. Universidade de Santiago de Compostela -USC, Santiago de Compostela (Galiza)

carmen.villarino@usc.es
\end{abstract}

\begin{abstract}
Resumo: As transformações e os novos desafios da sociedade atual são também visíveis no campo da educação em diferentes culturas. A criação de um Espaço Europeu da Educação Superior (EEES) contribuiu, em boa medida, para uma nova visão do processo de ensino e aprendizagem, com repercussões no nível da planificação, da(s) prática(s) docente(s) e dos modelos hegemônicos. Propomos, como principal objetivo, a elaboração de um projeto com a metodologia de Aprendizagem-Serviço (ApS) e de possível aplicação social -inicialmente, no âmbito da Universidade de Santiago de Compostela e na capital galega-, partindo da hipótese de que se trata de uma ferramenta com utilidade social para a inclusão cultural em âmbitos pedagógicos diversos. De entre as várias conclusões destacamos o compromisso social a partir de experiências do âmbito universitário e, nessa linha, a possibilidade de mudar a percepção social da formação em uma Faculdade de Filologia.
\end{abstract}

Palavras-chave: Cultura docente. Espaço europeu da educação superior. Serviço-aprendizagem.

Abstract: The transformations and new challenges faced by modern society are also evident in the educational field in different cultures. The emergence of a European Higher Education Area has greatly contributed to a new perspective of the teaching-learning process, with effects on the planning level, teaching practice(s) and hegemonic models. Our main aim here is to develop a project based on the Service-Learning methodology which can be implemented with a social purpose, starting at the University of Santiago de Compostela and the Galician capital city, on the assumption that it is indeed a tool of social utility towards cultural inclusion in various pedagogical spheres. Among the most relevant conclusions, we emphasize the importance of social commitment based on university experiences and, in this connection, we aim at changing social perception of training at a Faculty of Philology.

Keywords: Teaching culture. European higher education area. Service-learning.

\section{Para citar - (ABNT NBR 6023:2018)}

PARDO, Carmen Villarino. Novos desafios para uma geopolítica do conhecimento. O caso do espaço europeu de educação superior (EEES) e a metodologia de aprendizagem-serviço como recurso. Eccos - Revista Cientifica, São Paulo, n. 54, p. 1-17, e17265, jul./set. 2020. Disponível em: https://doi.org/10.5585/eccos.n54.17265. 


\section{Apresentação}

Nas últimas duas décadas, e de modo mais evidente no atual século, assistimos a uma série de mudanças ligadas a processos recentes de globalização e à nova sociedade do conhecimento -com diferentes efeitos e aplicações dependendo das sociedades em análise-, ao desenvolvimento das novas tecnologias (a chamada revolução tecnológica) e, entre outras, a uma grave crise econômica e social com repercussões muito amplas a nível mundial. Nessas circunstâncias assistimos, por diferentes vias, a debates sobre diferentes modelos produtivos, de consumo, energéticos, empresariais e também educativos (neste âmbito, e para o caso europeu, coincidiram em parte com a introdução do chamado Plano Bolonha ${ }^{l}$ ), que variam dependendo da geopolítica -de fato, o seu estabelecimento (e financiamento) oferece exemplos de 'decolonialidade do poder' e da centralidade e periferia de uns países em relação a outros.

As reformas que implicou a sua paulatina incorporação nos diferentes países europeus e os diferentes modelos de adatação vieram acompanhados de críticas e ampla repercussão no campo acadêmico mas também na mídia. No caso espanhol, alguns dos críticos com o processo, assinalavam que a reforma "consagró, en el contexto de la globalización neoliberal, la mercantilización de la universidad pública y entendida como "empresa de la excelencia"" (RODRÍGUEZ VICTORIANO, 2016); em alusão, também, ao uso de termos (““calidad', 'emprendedor' 'motivación', 'objetivos estratégicos', 'buenas prácticas'”) que o professor J.M. Rodríguez Victoriano qualifica de "rimbombantes y vacíos" e que, em sua opinião, “inundaran el campo semántico de la excelência” (ibidem).

Nos inícios do atual século, alguns trabalhos acadêmicos (NAYDORF, 2005; SANTOS, 2004) já chamavam a atenção para a irrupção de uma conceção economicista nas universidades ao analisarem -também com estudos de caso- as relações entre empresa e universidade (NAYDORF; SCHUGURENSKY, 2005; VILLARINO PARDO, 2011) ou aspetos da 'mercantilização do ensino superior' (SANTOS, 2004; DEREK, 2010) e anotavam, nessas dinâmicas, uma perda do papel da Universidade em relação à sociedade. Nesse contexto de "políticas neoliberais de mercadorização do conhecimento" (NAYDORF; SCHUGURENSKY, 2005, p. 270), e como recolhem Judith Naydorf e Daniel Schugurensky citando a C. Borches, "distintos diagnósticos sobre la universidad pública coinciden en un panorama de crisis. Crisis de identidad, crisis de legitimidad, crisis de relevancia, crisis de funcionalidad" (2005, p. 270)

\footnotetext{
${ }^{1}$ Este processo foi iniciado em 1999 quando 29 países europeus -entre os quais Portugal e Espanha- assinaram a chamada Declaração de Bolonha com o objetivo de criar, para 2010, um Espaço Europeu de Educação Superior-EEES- que, entre outros, facilitasse as equivalências entre os diferentes sistemas universitários europeus a diferentes níveis. Vid. LIMA ET ALII, 2008, p.7-36.
} 
Ao mesmo tempo, nesses anos da primeira década do século XXI em diferentes reuniões, foros e cimeiras -e os correspondentes relatórios ou declarações- sobre a implementação do Plano Bolonha no nível da União Europeia (Sorbona, Praga, Bergen) foram incorporando-se outras questões, como a dimensão social (fundamentalmente, a partir das conferências de Londres e Lovaina ${ }^{2}$ ) e a preocupação pela empregabilidade ou a repercussão externa do processo (RAUHVARGERS; DEANE; PAUWELS, 2009; WESTERHEIJDEN, 2010; IACOBUCCI, 2012).

Em paralelo, e mais recentemente, foram surgindo -em diferentes lugares do mundovozes e grupos críticos ${ }^{3}$ em relação a determinados efeitos dessas transformações que vive a universidade atual (e sua relação com a sociedade), tanto no âmbito da docência quanto, sobretudo, no da pesquisa (reivindicam outro tipo de conhecimento, criticam o capitalismo cognitivo, procuram uma nova geopolítica do conhecimento e uma maior democratização, questionam a ética da pesquisa na atualidade, etc.-MARTÍNEZ TEJERO, 2017). Em geral, coincidem no reconhecimento de uma 'mudança de cultura' dos/as professores/as universitários/as a raiz dessas novas dinâmicas. Para o coletivo Indocentia surgido na universidade espanhola de València (FERNÁNDEZ-SAVATER, 2016)" "las nuevas reglas del juego privilegian la investigación al tiempo que devalúan la docencia” (ibidem).

Essas diversas inquietudes, que visibilizam -a diferentes níveis- a criação de um Espaço Europeu da Educação Superior (EEES) mas também os debates atuais sobre que docência e que pesquisa para os desafios da(s) sociedade(s) contemporânea(s), implicam -no âmbito da docência universitária- uma nova visão do processo de ensino e aprendizagem. Este passa a estar mais centrado na aquisição de competências -que contempla o Plano Bolonha ${ }^{5}$ - e precisa de "metodologías de enseñanza-aprendizaje ativas y participativas que promuevan el aprendizaje reflexivo, autónomo, responsable y colaborativo de los alumnos" (UGARTE; NAVAL DURÁN, 2008/2009, 118, 122-123).

Uma amostra de mudança na cultura docente evidencia-se na proposta de uma focagem construtivista/cooperativa e contextual (aprendizagem-serviço, aprendizagem cooperativa, aprendizagem baseada em problemas) em lugar de optar por uma focagem expositiva

\footnotetext{
${ }^{2}$ Vid. BFUG-Bologna Follow-up Group, European Higher Education in a Global Setting. estratégia para a dimensão externa do Processo de Bolonha adoptada no encontro ministerial de Londres, Bruxelas, Comissão Europeia, 2007. ( $<$ https://media.ehea.info/file/Booklet/46/1/Bologna booklet 588461.pdf $>$ ); BBS-Benelux Bologna Secretariat, Bologna beyond 2010. Paper apresentado na conferência ministerial do Processo de Bolonha: Leuven/Louvain-la-neuve, 28-29/04/2009. Bruxelas: Comissão Europeia, 2010.<https://media.ehea.info/file/2009_Leuven_Louvain-laNeuve/91/8/Beyond_2010_report_FINAL_594918.pdf>.

${ }^{3}$ Entre outros: < http://www.scienceetbiencommun.org/> (Québec, criado em 2011); Gupo Ob̄lomoff (França, 2009; plataforma crítica com os modelos de pesquisa) ou Indocentia (Universitat de València).

${ }^{4}$ Vid. Também: <http://www.uv.es/cgt/COMUNITAT_UNIVERSITARIA/PDI/Indocentia cas.pdf>.

${ }^{5}$ Uma perspectiva recolhida, também, nas Conferências de ministros europeus de educação em Bergen (2005) e Londres (2007). Estas, foram duas das várias celebradas entre 1998 e 2010 (Paris, Bolonha, Praga, Berlim, Bergen, Londres e Leuven/Lovain-la-Neuve) com o objetivo de planificar o processo de Bolonha. Vid. Eurydice, 2010.
} 
(caraterizada pela informação unidirecional, individualismo, conhecer) -SANTOS REGO; LORENZO, 2014, p. 21-. Precisamente, Lorenzo/Mella/García/Varela (LORENZO et al., 2017) lembram que, em uma sociedade em mudanças e em uma economia do conhecimento como as atuais, pede-se à Universidade que "ofrezca una formación integral que redunde no solo en una formación técnica de calidad sino también en un aumento de la responsabilidad social y el compromiso cívico del alumnado".

Nesta filosofia insere-se a metodologia da Aprendizagem-Serviço; mais conhecida como service-learning no âmbito anglo-saxônico, em que tem sido mais desenvolvida desde inícios do s. $\mathrm{XX}^{6}$, com base nas propostas do pedagogo e filósofo John Dewey (SOTELINO, 2015).

\section{A aprendizagem-serviço (ApS): uma proposta de estudo de caso}

De entre as diversas definições apontadas, A. Sotelino Losada (2015, p.147) identifica a proposta por Josep M. Puig (PUIG et al. 2007) como a mais usada no espaço hispânico (e por instituições de prestígio na área). Assim, trata-se de uma "propuesta educativa que combina procesos de aprendizaje y de servicio a la comunidad en un solo proyecto bien articulado en el que los participantes se forman al trabajar sobre necesidades reales del entorno con el objetivo de mejorarlo" (PUIG et al., 2007, p.20).

É um projeto educativo com utilidade social, com potencialidades pedagógicas no EEES e que permite a ligação entre 'desenvolvimento de competências cívico-sociais na Universidade e a inserção laboral dos alunos/as ${ }^{7}$.

Apresentamos, a seguir, uma proposta concreta que pretende ser um estudo de caso e que, eventualmente e se as condições forem as oportunas, poderá vir a ser aplicado como um exemplo prático desta metodologia.

\subsection{Justificação e Enquadramento}

No quadro do Espaço Europeu de Educação Superior (EEES), a oferta acadêmica de estudos lusófonos da Universidade de Santiago de Compostela (USC) -no nível da Graduação-

\footnotetext{
${ }^{6}$ A sua incorporação no âmbito europeu é da década de 1990 e, no caso espanhol, nos inícios do s. XXI (existe, desde 2010, uma Red Española de Aprendizaje Servicio: https://aprendizajeservicio.net/). Para conhecer o desenvolvimento histórico e espacial de sua implantação, vid. SOTELINO (2015) e, mais especificamente para o âmbito latino-americano, TAPIA (2010).

${ }^{7}$ De acordo com os objetivos do projeto "Aprendizaje-servicio e innovación en la Universidad. Un programa para la mejora del rendimiento académico y el capital social de los Estudiantes”, coordenado por M.A. Santos Rego e M.M. Lorenzo Moledo, da USC. Vid. https://www.researchgate.net/project/APRENDIZAJE-SERVICIO-E-INNOVACION-EN-LA-UNIVERSIDAD-UN-PROGRAMAPARA-LA-MEJORA-DEL-RENDIMIENTO-ACADEMICO-Y-EL-CAPITAL-SOCIAL-DE-LOS-ESTUDIANTES
} 
está fundamentalmente centrada na Graduação em Línguas e Literaturas Modernas (GLLMP), no itinerário de "Língua Portuguesa e Literaturas Lusófonas"8 -que oferece a Faculdade de Filologia-, ainda que também existe uma oferta (mínima) na Faculdade de Ciências da Educação da USC ${ }^{9}$.

A partir do ano acadêmico 2009-2010, a Faculdade de Filologia da USC oferece cinco títulos de graduação que compartilham uma estrutura comum integrada por: 1. Módulo de formação básica (60 créditos ECTS); 2. Maior (120 créditos ECTS); 3. Minor (48 créditos ECTS; que combina um Módulo Complementar de 24 ECTS e um Módulo Opcional -também de 24 ECTS-; 4. Trabalho de Fim de Graduação -TFG- $(12 \text { créditos ECTS })^{10}$.

O itinerário de "Língua Portuguesa e Literaturas Lusófonas", dentro da GLLMP"1, pretende garantir, num nível geral avançado, a aquisição e compreensão dos conhecimentos relativos aos campos lingüístico, sociocultural e literário do âmbito lusófono, tendo também presentes as relações entre a Galiza e a Lusofonia, tal e como se indica na Memória do Título ${ }^{12}$ e em sua apresentação pública nas páginas web da Faculdade e da Universidade.

De entre as matérias específicas de estudos lusófonos, encontramos as seguintes (todas elas com 6 créditos ECTS):

a) Módulo Básico: Língua Portuguesa (1 e 2)

b) Maior (120 créditos ECTS): Língua Portuguesa (3,4,5), Literaturas de língua portuguesa, Cultura Portuguesa, Literatura Portuguesa (1,2,3), Cultura do Brasil, Cultura dos PALOP, Literatura Brasileira, Gramática Portugues $(1,2)$, Literaturas Comparadas na Lusofonia e Sociologia das Literaturas de Língua Portuguesa.

3) Minor (48 créditos ECTS; para aquelas pessoas que façam um Maior em outra Graduação ou itinerário diferente ao de Português), conta com a possibilidade de estudar um ou dois dos módulos de 4 matérias que se oferecem: Estudos Lusófonos 1 e Estudos Lusófonos 2.

Os/As alunos/as que fazem um Maior na Graduação em Linguas e Literaturas Modernas: Português podem optar por uma especialização no âmbito lusófono através da Modalidade Maior Plus ${ }^{13}$, que inclui a possibilidade de escolher entre as seguintes disciplinas:

\footnotetext{
${ }^{8} \mathrm{Vid} .<\mathrm{http}: / /$ www.usc.es/gl/centros/filoloxia/titulacions.html?plan=12953\&estudio=12954\&codEstudio=12609\&valor=9>. Neste curso há diferentes itinerários: Português, Alemão, Francês, Italiano e Românicas.

${ }^{9}$ Vid. $<$ http://www.usc.es/es/centros/cc educacion/titulacions.html?plan=14084\&estudio=14085\&codEstudio=13639\&valor=9 $>$.

${ }^{10}$ Vid. A resolução de 16 de fevereiro de 2010 da Universidade de Santiago de Compostela, pela qual se publica o plano de estudos da Graduação em Línguas e Literaturas Modernas, publicada no Boletín Oficial del Estado $<$ http://www.boe.es/boe/dias/2010/03/05/pdfs/BOE-A-2010-3686.pdf>-; com data de 05/03/2010.

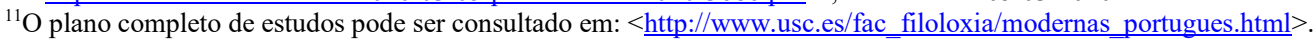

${ }^{12}$ Vid. $<$ http://www.usc.es/export/sites/default/gl/servizos/sxopra/memorias_graos_USC/Lingua_e_Lit_Modernas.pdf $>$.

${ }^{13} \mathrm{Vid}$. <http://www.usc.es/fac_filoloxia/modernas_portugues.html $>$.
} 
"Pragmática e Análise de textos em língua portuguesa", "Tecnologias aplicadas à língua portuguesa", "Edição de textos em língua portuguesa", "Português: teoria e prática da tradução", "Planificação Cultural”, "Indústrias e Instituições Culturais", "Dinâmicas socioculturais da Lusofonia" e "Asessoria e consultoria culturais na Lusofonia".

\section{$\underline{2.1 .1 \text { Estudo de caso }}$}

É neste quadro alargado de oferta docente ligada ao âmbito lusófono que (se) encaixa a realização de um estudo de caso de Aprendizagem-serviço, aqui proposto ${ }^{14}$, aplicado a duas dessas matérias: "Cultura do Brasil" e "Dinâmicas Socioculturais da Lusofonia" como modos de oferecer aos/às estudantes a possibilidade de práticas efetivas de 'decolonialidade' do poder, do saber, do gênero e das estruturas educativas habituais. Os motivos da escolha devem-se ao próprio teor das mesmas, à natureza diversa dos grupos de alunos/as que habitualmente as integram e ao fato de ter sido docente ${ }^{15}$ delas nos últimos anos.

A proposta implica que aquelas pessoas inscritas nestas disciplinas, que assim o decidirem, possam aproveitar os conhecimentos adquiridos em sua formação curricular para tentarem fortalecer e/ou mudar também - no sentido de pedagogias que proponham uma transformação educativa-, determinadas dinâmicas -dentro e fora da sala de aula-, que visem uma consideração dos/as alunos/as como cidadãos e cidadãs que sejam responsáveis, proativos, colaborativos, críticos, solidários, inclusivos, respeituosos com a comunidade e o entorno e abertos às várias diversidades, a partir das oportunidades criadas em uma universidade pública com vontade explícita de serviço público.

A disciplina de "Cultura do Brasil" ( $2^{\circ}$ ano, $2^{\circ}$ semestre) é oferecida para alunos/as da GLLM: Português (Modalidade Maior, 120 ECTS) e, na Modalidade Minor (no Módulo opcional de Estudos Lusófonso II, 24 ECTS), para as pessoas das outras Graduações (em Língua e Literatura inglesas; em Língua e Literatura Espanholas; em Língua e Literatura Galegas; ou em Estudos Clássicos) e dos outros quatro itinerários da GLLMP (alemão, italiano, francês, românicas). E "Dinâmicas Socioculturais da Lusofonia" ( $4^{\circ}$ ano, $1^{\circ}$ semestre) é uma matéria da Modalidade Maior Plus de "Especialização em Língua e Literaturas Lusófonas” (48 ECTS), da GLLMP.

\footnotetext{
${ }^{14}$ Este pode complementar a proposta do projeto Cult!, apresentado pelos colegas Elias J. Feijó Torres e M. Felisa Rodríguez Prado, em uma outra proposta de atividade formativa de ApS, também aplicável aos Estudos Lusófonos na GLLM, da USC.

${ }^{15}$ No caso de "Cultura do Brasil", habitualmente partilhada com o/a colega que, em cada período, ocupa o posto de Leitor/a do Brasil na USC.
} 


\subsection{Necessidade}

A tradição ibero-americanista da USC viu-se intensificada desde 2004 e, mais especificamente, a partir da Declaração de Compostela ${ }^{16}$, com que se encerrou a Conferência Ibero-americana de Reitores (Universidade de Santiago de Compostela, fevereiro de 2004), que consolidou a USC “como bisagra institucional no ámbito iberoamericano de educación superior" (http://www.usc.es/gl/servizos/ore/) e que, como se indica na Memória de Responsabilidade Social da Universidade de Santiago de Compostela (2005), foi uma iniciativa que permitiu à Universidade da capital galega consolidar sua liderança “a favor del desarrollo de un Espacio Común de Educación Superior de la Unión Europea, América Latina y el Caribe (UEALC)" ${ }^{\prime 17}$.

Verifica-se que, nos últimos anos, a USC em geral e a Faculdade de Filologia em particular, vêm sendo um espaço amplamente escolhido por estudantes de origem estrangeira, através de programas Erasmus+ (da União Europeia) e de outro tipo de convênios entre instituições de ensino superior com a USC (fundamentalmente, através de convênios bilaterais ${ }^{18}$ ). Segundo os dados facilitados pela Área de Qualidade e Melhora de Procedimentos da $\mathrm{USC}^{19}$ para a primeira parte da década de 2010 -em que se implementou o Plano Bolonha na USC-, no ano acadêmico 2011-2012 o número de alunos/as estrangeiros/as representou $28,39 \%$ das pessoas inscritas na USC; $15,09 \%$ em 2012-2013; 25,50\% em 2013-2014; 16,43\% em 2014-2015 e desceu até 7,61\% em 2015-2016. O número de estudantes estrangeiros que frequentam cursos na Faculdade de Filologia é, em geral, superior à média da Universidade considerando o mesmo período-: no ano acadêmico 2011-2012 5,05\%; em 2012-2013, 4,72\%; em 2013-2014, 2,39\%; 3, 21\% em 2014-2015 e desceu até 1,73\% em 2015-2016.

Existem programas, cursos e atividades da própria USC -para além de outros, de iniciativa privada- destinados a facilitarem a acolhida de alunos/as estrangeiros/as; entre os quais, a Feira de Estudantes Internacional-International Day ou o programa de intercâmbio linguístico-cultural Volangteer, ambos com indicações explícitas para os/as alunos/as do Programa Erasmus (Erasmus +$)^{20}$.

\footnotetext{
${ }^{16}$ Disponível em: <http://www.usc.es/gl/goberno/reitoria/iberoam.html>.

${ }^{17}<$ http://www.usc.es/export9/sites/webinstitucional/es/info_xeral/memoria/descargas/mrs05_es.pdf $>$; p. 122

${ }_{18} \mathrm{Vid}$. < http://www.usc.es/gl/perfis/internacional/mobilidade/bilateral.html $>$.

${ }^{19}$ Dados solicitados através de correio eletrônico interno.

${ }^{20} \mathrm{Vid} .<\mathrm{http}: / /$ www.usc.es/gl/perfis/internacional/acollida.html\#act>.
} 
No estudo de caso concreto que propomos para este trabalho, pretendemos organizar ações de Aprendizagem-Serviço nas duas matérias selecionadas, com alunos/as procedentes de convênios bilaterais de universidades brasileiras.

Em geral, observamos que estes alunos e alunas têm uma maior dificuldade para a inserção sociocultural no espaço da comunidade universitária e da comunidade local santiaguesa. Habitualmente, incorporam-se unicamente um semestre e o processo de aclimatação aos modos de vida e de trabalho na USC é relativamente lento. Às habituais dificuldades derivadas da distância com os respetivos lugares de procedência (maior, em geral, do que aquela que separa outros alunos estrangeiros procedentes, basicamente, de países da União Europeia), à mudança de estações no caso do hemisfério sul, aos hábitos culturais (gastronômicos, horários, etc.) e ao fato de serem menos numerosos (tanto em relação à origempaís quanto à origem-universidade) que os/as alunos/as do programa Erasmus, somam-se outras práticas da cultura acadêmica do país de origem que fazem com que o período real na USC seja, de modo geral, um laboratório de experimentação intenso e relativamente breve. Para isto, parece mais adequado um acompanhamento mais próximo e de cumplicidades com alguma pessoa nativa que possa ser a companheira de uma inserção com maior sucesso.

Da nossa prática docente observamos que estas pessoas - de modo geral- não conseguem rentabilizar muitas das oportunidades que, em nossa opinião, se derivam de constatar que a Universidade de Santiago de Compostela é, de fato, uma ponte cultural: por ser uma universidade galega que oferece aos seus estudantes uma cultura vinculada (por questões histórico-culturais e também de tipo socioeconômico e demográfico) de modo evidente com a brasileira e por contar com duas línguas oficiais, o castelhano e o galego, sendo esta uma variante da comum língua e veículo natural de integração no espaço lusófono.

Este tipo de mobilidade internacional pretende (e não apenas no nível dos/as estudantes de Graduação) contribuir para a construção do Espaço Comum de Educação Superior União Europeia-América Latina-Caribe (Caraíbas), através da cooperação ibero-americana, com ações que visam impulsionar a melhora da qualidade da avaliação, da equivalência de estudos nos diferentes níveis e, entre outras, a intensificação dos programas específicos de mobilidade "aproveitando o valor agregado oferecido pelas nossas línguas comuns" para diminuir as barreiras burocráticas derivadas da mobilidade, tal e como recolhe a referida Declaração de Compostela $(<\mathrm{https}: / /$ www.usc.gal/gl/goberno/reitoria/iberoam_pt.html $>)$. 


\subsection{Serviço}

Os/As estudantes da USC inscritos/as nessas duas disciplinas selecionadas para o desenvolvimento desta $\mathrm{ApS}$ contam com diferentes níveis de formação prévia, dependendo das escolhas curriculares de cada um/a e das condições de procedência (social, familiar e universitária).

Com este projeto de Aprendizagem-Serviço, pretende-se que esses/as alunos/as da própria USC ponham ao serviço da integração destes outros alunos e alunas brasileiros /as -que estudem, quando menos numa primeira fase da ApS, na Faculdade de Filologia- os seus conhecimentos, adquiridos já em matérias de Língua, de Literatura e de Cultura lusófonas.

Propomos começar por este Centro para que funcione como Projeto Piloto e que, em futuras edições, possa alargar-se a outras Faculdades da USC e, se for de interesse e oportuno, desenvolver esta ApS no nível de toda a instituição. Deste modo, a USC poderia aproveitar o capital simbólico derivado da sua tradição e história como Universidade de referência galega e não apenas ${ }^{21}$ para converter os seus alunos e alunas, próprios e visitantes, em mediadores culturais, com conhecimentos e práticas que possam converter-se em uma mais-valia para uma Universidade com mais de 520 anos. E os/as estudantes estrangeiros -neste caso, brasileiros e brasileiras- podem converter-se em antenas no exterior para a USC: sendo, a meio-longo prazo, embaixadores de fato da instituição e da sociedade galegas nos respetivos lugares de origem e/ou residência.

Ao analisarmos a atenção dada a estes/as alunos/as nas informações que a Univ. de Santiago de Compostela veicula através da página web institucional, observamos que as indicações visam, sobretudo, informar os futuros alunos de que precisam pertencer a uma universidade que tenha convênio assinado com a $U_{S C}^{22}$ e que essa instituição o apresente como aluno/a para mobilidade de um ou dois semestres ${ }^{23}$, para além de contar com as solicitações necessárias para se candidatar e dos serviços que a USC oferece às pessoas que finalmente conseguem vir nessa condição. Estes serviços ${ }^{24}$ concentram-se em atender as necessidades pessoais de tipo acadêmico (através das Unidades de Gestão Acadêmica, Bibliotecas Universitárias) alojamento (através do Serviço Universitário de Residências), manutenção (cafetarias e refeitórios universitários), idiomas (Centro de Línguas Modernas, Cursos

\footnotetext{
${ }^{21}$ Até este momento, a única mulher Doutora Honoris Causa da USC, nos mais de 500 anos de história, é -desde 1998- a escritora brasileira Nélida Piñon. Vid. VILLARINO PARDO, 2020 (no prelo); <http://tv.usc.es/serial/index/id/176>

${ }^{22}$ Pode consultar-se a listagem completa em: http://www.usc.es/gl/servizos/convenios/cibrasil.html

${ }^{23}$ Vid. $<$ http://www.usc.es/gl/perfis/internacional/mobilidade/bilateral.html $>$.

${ }^{24} \mathrm{Vid} .<$ http://www.usc.es/gl/perfis/internacional/servizos.html $>$.
} 
Internacionais de língua), acesso a internet (acesso wi-fi, aulas de informática), atividades de lazer e tempo livre (atividades culturais e esportivas, de voluntariado) e especial atenção para os/as alunos/as com necessidades especiais.

Esta ApS pretende implementar a inclusão cultural e o espírito de intercâmbio refletido, entre outros, na Declaração de Compostela e efetivar as práticas dos intercâmbios internacionais em termos de trocas culturais e educativas reais e de melhor inserção na comunidade universitária e na cidade de Santiago de Compostela (eventualmente, também na de Lugo, onde a USC tem também um campus), partindo dos conhecimentos adquiridos na formação acadêmica daqueles/as alunos/as inscritos nas disciplinas docentes indicadas e que optem voluntariamente por escolher trabalhar nesta ApS.

\subsection{Aprendizagem}

O/A estudante pode optar (sempre de modo voluntário) pela metodologia da ApS no caso das duas matérias. Se o/a aluno/a assim o considerar e a natureza do trabalho estiver acorde com o previsto pela Comissão Acadêmica da Faculdade de Filologia para estes casos, entendemos que poderia ser útil que esta Aprendizagem-Serviço pudesse continuar o seu desenvolvimento através de um Trabalho de Fim de Graduação (TFG) -obrigatório para completar a formação de Graduação nas universidades espanholas-, porque permitiria um maior tempo de trabalho da ApS em relação ao de uma matéria semestral.

A Aps que propomos teria como título “Oi!", porque o uso desta forma de cumprimentar -de maneira informal- no Brasil pretende criar empatia com a pessoa recém chegada e seria um modo de dar as boas-vindas à USC e a Santiago de Compostela aos alunos e alunas procedentes do Brasil.

A ApS pode ser desenvolvida a nível individual ou grupal. Propomos que aqueles/as alunos/as que decidam fazer voluntariamente a ApS participem ativamente na definição do projeto, para promover sua implicação de modo integral -com reflexo nos seus curricula acadêmicos- e que mostrem sua habilidade e capacidade em identificar a necessidade do entorno e sejam capazes de propor estratégias e ações para obter soluções, assim como evidenciar a responsabilidade de cada um/a deles/as no processo.

O projeto deve incluir, entre outras, as seguintes fases:

a) Apresentação do projeto em sala de aula no início do calendário acadêmico da(s) matéria(s). 
b) Criação de grupos de trabalho para definir e concretizar a ApS com aquelas pessoas que decidam unir-se ao projeto.

Pretende-se trabalhar competências transversais e específicas (já incluídas no programa docente da disciplina, aprovado oficialmente pela Faculdade ${ }^{25}$ ), que tenham a ver, entre outros, com os modos de trabalho cooperativo e em equipe.

c) Formulação, o mais completa possível, da necessidade detetada.

d) Análise conjunta para implicar os possíveis (e necessários) sócios na ApS e desenvolver as competências necessárias -fundamentalmente através de trabalho cooperativo- para verbalizarem as aprendizagens adquiridas e mostrarem os benefícios para esses possíveis sócios.

e) Estabelecer reuniões de trabalho- entre alunos/as envolvidos no projeto e a docente da matéria- com a Equipe da Direção da Faculdade de Filologia, com os responsáveis pelas Relações Exteriores (no nível administrativo e político) da USC, com a Área de Qualidade e com o Serviço de Participação e Integração Universitária da mesma instituição para tentar convertê-los, de fato, em sócios cúmplices do projeto e desenvolver com eles -no decurso da elaboração da ApS- umha relação de parceria.

Um dos alunos ou alunas -no caso de trabalhar em equipe- será a pessoa encarregada de secretariar -por escrito ou com gravação em vídeo- as sessões de trabalho para ter um acompanhamento confiável do processo com as diferentes tomadas de decisão e os procedimentos e resoluções adotados.

f) Dos sócios procura-se, inicialmente, que ofereçam alguns dos possíveis dados relativos aos/às estudantes procedentes do Brasil que estão na Faculdade de Filologia nesse semestre. E se, eventualmente, nesse período houver menos alunos/as brasileiros/as do que estudantes dispostos a participarem na ApS, procurar-se-á contato com outros centros da USC em que os houver.

g) Encontros formais e informais com os/as estudantes do Brasil para definir objetivos em relação à aprendizagem e ao serviço e poder começar as atividades da ApS e atender também as suas propostas.

h) Estudantes da disciplina escolhida e docente(s) devem planificar e desenvolver algumas dessas atividades que serão, eventualmente, ampliadas a partir dos encontros de trabalho já com as pessoas brasileiras.

${ }^{25}$ Estão disponíveis em: http:/www.usc.es/gl/centros/filoloxia/programas.html?plan=12953. 
i) Tratar, em todo o processo da ApS, que os/as alunos/as sejam conscientes das próprias limitações e que, tanto na definição quanto nas fases de execução do projeto, as propostas sejam factíveis e realistas.

\subsection{Atividades concretas (de aprendizagem e de serviço)}

Algumas das atividades para desenvolverem os/as alunos na ApS (galegos/as e brasileiros/as) seriam estas:

a) Elaboração de um blogue ${ }^{26}$ de experiências mistas, galego-brasileiras, trabalhado com materiais de origem diversa: textos escritos, vídeos, recolha de notícias da imprensa e da internet; gravar (com celulares) entrevistas breves com diferentes pessoas que trabalhem no âmbito das relações culturais Galiza-Brasil em Santiago de Compostela ou que, eventualmente, estejam aqui (cantores e músicos dos dois espaços, com experiência nestas relações; e outras pessoas -imigrantes brasileiros morando aqui, imigrantes galegos retornados do Brasil ou visitantes brasileiros a Santiago de Compostela- que possam falar da cultura de ambos os países).

A construção de espaços informais de relacionamento como uma página de facebook ou um grupo de whatsapp -entre outras redes sociais- poderiam contribuir também para apoiar esse trabalho.

b) Criação de um foro na Aula Virtual da matéria ${ }^{27}$, coordenado por algum/a aluno/a da ApS -previamente escolhido, e com conhecimento da docente-, em que se valorize a motivação para fomentar a participação ativa do resto de alunos/as da(s) matéria(s) que não trabalhem na $\mathrm{ApS}$ e que, assim, possam enriquecer sua formação com o olhar de quem tem parte da aprendizagem incorporada e não trabalha em sua aplicação para este serviço concreto. Eles/as, em certo modo, podem ser considerados -se assim o entenderem- como observadores que ajudem a matizar ou reorientar a ApS para uma melhor formulação e otimização da mesma.

$\mathrm{Na}$ avaliação ter-se-á em conta a capacidade do/a aluno/a coordenador/a à hora de criar mecanismos de implicação, motivação, moderação e posta em prática da aprendizagem para o serviço proposto. Dependendo do funcionamento do foro, aqueles/as alunos/as que se impliquem no mesmo -sem estarem diretamente envolvidos

\footnotetext{
${ }^{26}$ Mesmo pode ser incorporado ao site da USC: $<$ https://brasilgaliza.wixsite.com/brasilgaliza $>$. Vid. RANGEL, 2018.

${ }^{27}$ Ferramenta disponível em uma plataforma moodle da USC, que oferece um espaço do campus virtual para partilharem alunos/as e docente(s) de cada matéria.
} 
no trabalho da ApS- podem ser recompensados em termos de valorização positiva em sua avaliação.

c) Preparação e produção de um programa para emitir na TV da USC (http://tv.usc.es/) ou um programa de rádio que possa ser oferecido como atividade para alguma das emissoras que contam com programação própria em Santiago.

d) Encontros com a(s) comunidade(s) imigrante(s) brasileira(s) de Santiago de Compostela, para tentar pôr em contato o(s) estudante(s) nativo(s) e o(s) estudante(s) brasileiro(s) que participam da ApS com pessoas imigrantes brasileiras que estejam morando em Santiago de Compostela. Os/As alunos/as devem ser capazes de explicar a estas pessoas em que consiste a Aprendizagem-Serviço em que trabalham e participar de encontros com as agrupações de imigrantes de que possam tirar ideias para acrescentarem ao serviço que a ApS oferece e enriquecer o próprio processo de aprendizagem.

Trata-se de avaliar a capacidade de comunicação e as habilidades relacionais como parte do processo de aprendizagem e serviço e, ao mesmo tempo, de um esforço de responsabilidade docente e de transferência de conhecimento em relação à comunidade que acolhe uma instituição pública como a Universidade de Santiago de Compostela. da ApS.

A docente deve vigiar, em todo o momento, que se trate de uma aprendizagem-serviço, em que não se perca o equilíbrio entre o crescimento pessoal no nível dos conteúdos adquiridos e de sua aplicabilidade com o fim de garantir um serviço de qualidade.

A responsabilidade e o compromisso do/a aluno/a que decide participar do processo da ApS devem ser, igualmente, avaliados desde o primeiro momento em que a pessoa assume participar da mesma e que será envolvida na planificação integral da Aprendizagem-Serviço proposta.

As diferentes atividades também serão avalidas, no processo e nas tarefas concretas propostas em algum caso; e devem estar contempladas no programa e no guia docente -ambos, obrigatórios na Faculdade de Filologia- da(s) matéria(s) como uma possibilidade.

No caso da atividade exposta em 5.a), entendemos que, por si próprio, o blogue não tem um importante valor acadêmico, mas, do mesmo modo que a proposta de elaborar um possível 
portfólio -individual ou coletivo, dependendo da proposta, cuja elaboração será avaliada positivamente- trata-se, fundamentalmente, de avaliar as competências e destrezas concretas desenvolvidas na deteção de uma rede de fatores que possam ajudar a concretizar alguns aspetos da aprendizagem no serviço proposto através da ApS e, em paralelo, de que as experiências reunidas no blogue sirvam como uma lembrança pessoal que possa transmitir, com o tempo, as emoções, afetos e vivências pessoais compartilhadas ao longo do processo de trabalho.

Para a tarefa indicada no item 5.b), a avaliação terá em conta a capacidade da pessoa coordenadora à hora de criar mecanismos de implicação, motivação, moderação e posta em prática da aprendizagem para o serviço proposto. De novo, e dependendo do funcionamento do foro, aqueles/as alunos/as que se implicarem no mesmo -sem integrarem diretamente o trabalho da ApS- podem ser recompensados em termos de valorização positiva em sua avaliação.

Nas reuniões com os sócios cúmplices -Direção da Faculdade de Filologia e diferentes serviços da USC envolvidos- trata-se de avaliar a capacidade de comunicação e as habilidades relacionais como parte do processo de aprendizagem e serviço, com atenção também para o registo oral e o domínio dos conteúdos que sejam expostos e o modo de os apresentar e de serem capazes de os adatar aos diferentes espaços e situações em que tiverem lugar.

A profissionalidade do serviço oferecido e a capacidade para alterar/mudar aspetos do mesmo em função das necessidades ou dos problemas detetados serão elementos fundamentais na consideração da ApS.

Valorizar-se-á, de modo importante, a proatividade do/a aluno/a, o trabalho colaborativo e a capacidade de liderança que demonstre, assim como as atitudes para o debate, a negociação e o trabalho em cooperação.

A docente quer propor, além da avaliação numérica para a disciplina em que a ApS se desenvolver -ou o Trabalho de Fim de Graduação, se for o caso-, uma avaliação crítica -e mesmo a possibilidade de considerar também uma autoavaliação- da parte daqueles agentes que participaram em termos institucionais da $\mathrm{ApS}$ e dos próprios/as alunos/as colegas seus na matéria selecionada.

O compromisso do/a aluno/a e da docente devem fazer com que essas críticas sejam também incorporadas à planificação e proposta de uma nova $\mathrm{ApS}$ noutra possível ocasião.

O reconhecimento da $\mathrm{ApS}$, se a avaliação for positiva, entendemos que deve vir também através de um diploma ou certificado em que figurem as entidades colaboradoras; sendo preciso estabelecer algum tipo de acordos com estas para que assim possa ser feito. Esta visualização de um certo capital simbólico pode legitimar mais a escolha de uma ApS como metodologia de trabalho nas nossas aulas. 


\section{Considerações finais}

Pretendemos que este projeto educativo tenha uma utilidade social, de modo que as atividades que se desenvolvam na ApS permitam resolver uma possibilidade detetada no âmbito da comunidade universitária e local e, ao mesmo tempo, capacitem alunos e alunas para aplicarem -em termos de responsabilidade e ação social- os conhecimentos aprendidos, também nas tarefas de mediadores culturais.

Essas competências e destrezas deveriam ser úteis também para abrir novos horizontes laborais para os/as alunos/as, com capacidade para tarefas ligadas à planificação, consultoria e assessoramento cultural na Lusofonia e, assim, mudar também a perceção social da formação em uma Faculdade de Filologia.

Com a entrada em vigor na USC dos planos acadêmicos ligados ao Plano Bolonha, os Estudos Lusófonos -nomeadamente no itinerário que apresentámos do Maior Plus- têm apostado por uma linha que aponta para uma viragem dos estudos da literatura para os estudos da cultura, em consonância com o acontecido em várias universidades do mundo -também nos níveis da pesquisa e da docência-.

Essa tendência (que apontam, entre outras, as propostas dos programas das disciplinas de "Planificação Cultural”, "Indústrias e Instituições Culturais", "Dinâmicas Socioculturais da Lusofonia" e "Assessoria e consultoria culturais na Lusofonia", do Maior Plus "Especialização em Lingua Portuguesa e Literaturas Lusófonas") mostra uma aposta relativamente visível e firme para uma futura inserção laboral das pessoas graduadas neste itinerário, com maior amplidão de seu espaço de possíveis $^{28}$, a partir da formação especializada em uma universidade galega com especial interesse e foco em mostrar uma geopolítica do conhecimento que passe por descentralizar a ideia de determinados centros que se mostram como 'metrópoles' de um determinado modo de abordar o conhecimento.

Esta ApS pretende ser uma experiência enriquecedora em termos de conhecimentos e de aplicabilidade dos mesmos no terreno da participação e da responsabilidade social no seio da USC e da própria cidade de Santiago de Compostela (ou da de Lugo, como sedes dos dois campus da USC).

${ }^{28}$ Com a possibilidade, em alguns casos, de a complementar através de práticas externas. 


\section{Referências}

DEREK, B..Universidades a la venta. La comercialización de la educación superior, (trad. Vicent Climent), Valencia: PUV, 2010.

EURYDICE. La educación superior en Europa 2010: el impacto del proceso de Bolonia. Agencia Ejecutiva en el Ámbito Educativo, Audiovisual y Cultural (EACEA P9 Eurydice), 2010.

$<$ http://eacea.ec.europa.eu/education/eurydice/documents/thematic_reports/122ES.pdf $>$.Acess o em: 3 mar 2020.

FERNÁNDEZ-SAVATER, A.. Disciplinar la investigación, devaluar la docencia: cuando la Universidad se vuelve empresa. El Diario. Madrid. 19/02/2016. Em linha:

http://www.eldiario.es/interferencias/Disciplinar-investigacion-devaluar-docenciaUniversidad_6_486161402.html. Acesso em: 8 jan 2020.

IACOBUCCI, G. O Processo de Bolonha: um modelo europeu de reforma do ensino superior?: O impacto nas outras regiões do mundo (o caso da América Latina e do Brasil). 2012. 133p. Dissertação de Mestrado em Letras. Universidade de Coimbra, Coimbra.

LIMA, L.; AZEVEDO, M.L. Neves de; CATANI, A. Mendes. O processo de Bolonha, a avaliação da educação superior e algumas considerações sobre a Universidade Nova. Avaliação: Revista da Avaliação da Educação Superior, Campinas, 13 (1), mar., 2008, p.736. http://www.scielo.br/scielo.php?script=sci_arttext\&pid=S1414-40772008000100002. Acesso em: 3 fev.2020.

LORENZO MOLEDO et al.. Investigar para institucionalizar el aprendizaje servicio en la universidad española. RIDAS. Revista Iberoamericana de Aprendizaje Servicio, Universitat de Barcelona, 3, 2017, p.118-130. http://revistes.ub.edu/index.php/RIDAS/article/view/19112. Acesso em: 19 jan. 2020

MARTÍNEZ TEJERO, C. Questionar a investigaçom, reivindicar outro conhecimento. Capitalismo cognitivo e ética da investigaçom na atualidade. I Colóquio Internacional Galabra "Tecendo Rede. Sentidos, aplicações e cooperação na investigação em ciências humanas e sociais”, Braga-Universidade do Minho, 09-10/01/2017.

NAYDORF, J. Los cambios en la cultura académica a partir de los procesos de vinculación universidad-empresa en las universidades públicas. 2005. 415p. Tese de Doutoramento em Filosofia e Letras, Universidad de Buenos Aires, Buenos Aires. http://repositorio.filo.uba.ar/handle/filodigital/1370.

PUIG, J.M.; et al.. Aprendizaje servicio. Educar para la ciudadanía. 1 ed. Barcelona: Octaedro, 2007.

RANGEL, V. BrasilGaliza: Ensinar literatura brasileira na Galiza, algumas considerações Opiniães, 13, 2018, p.82-101.mailto:https://doi.org/10.11606/issn.2525-

8133.opiniaes.2018.148641. 
RAUHVARGERS, A.; DEANE, C.; PAUWELS, W. Bologna Process Stocktaking Report 2009: Report from working groups appointed by the Bologna Follow-up Group to the Ministerial Conference, Leuven/Louvain-la-Neuve, 28-29/04/2009, 2009. https://media.ehea.info/file/2009_Leuven_Louvain-laNeuve/94/7/Stocktaking_report_2009_FINAL_594947.pdf. Acesso em: 29 jan 2020.

RODRÍGUEZ VICTORIANO, J.M. La praxis de la excelencia universitaria entre la paranoia de sus promotores y la culpa de sus víctimas: Hacia la recuperación del deseo docente y la universidad pública. 2016. https://josemrodriguezvictoriano.wordpress.com/2016/12/09/lapraxis-de-la-excelencia-universitaria-entre-la-paranoia-de-sus-promotores-y-la-culpa-de-susvictimas-hacia-la-recuperacion-del-deseo-docente-y-la-universidad-publica/. Acesso em: 11 fev. 2020.

SANTOS, B. de Sousa. La Universidad en el siglo XXI: para una reforma democrática y emancipadora de la universidad. 1 ed. Trad. Ramón Moncada. Bogotá: Cuadernos Pedagógicos de la Escuela 6, 2004.

SANTOS REGO, M.A.; LORENZO MOLEDO, M.M.. Obradoiro de aprendizaxe-servizo na Universidade. Curso Programa Formación de Profesorado, Universidade de Santiago de Compostela, 2014.

SOTELINO LOSADA, A. A aprendizaxe-servizo en perspectiva. John Dewey como referente histórico. Sarmiento, 18-19, 2015, p.145-162. http://ruc.udc.es/dspace/handle/2183/16953.

TAPIA, M.N.. La propuesta pedagógica del aprendizaje-servicio: una perspectiva latinoamericana. Tzhoecoen. Revista Cientifica, 3(5), 2010, p. 23-43.

http://www.ugr.es/ ctriguer/Secundarias/Master/Curriculum/Bases\%20del\%20ApS.pdf.

UGARTE, C.; NAVAL DURÁN, C.. El desarrollo de las competencias cívicas en la universidad. Cuestiones Pedagógicas, nº.19, 2008/2009, p. 115-140.

VILLARINO PARDO, C. Posición autoral y repertorio(s) en el campo literario brasileño: Nélida Piñon y $O$ calor das coisas (1980). En RIVAS, A.. Nélida Piñon en la república de los sueños. Salamanca: Servicio de publicaciones de la USAL-CEB, 2020. (No prelo).

VILLARINO PARDO, C. Da academia ao negócio. Aplicações à empresa da pesquisa em Humanidades. Em REBELO, H. (coord..). Lusofonia: Tempo de Reciprocidades.Vol.1. Lisboa: Afrontamento, 2011, p. 259-264.

WESTERHEIJDEN, D.F. et al., The Bologna Process Independent Assessment - The first decade of working on the European Higher Education area, Comissão Europeia, 2010.https://www.researchgate.net/publication/259101023_The_first_decade_of_working_on the_European_Higher_Education_Area_The_Bologna_Process_Independent_Assessment__Executive_summary_overview_and_conclusions. Acesso em: 23 jan 2020. 